\title{
ANALYSIS OF SOLAR PHOTOVOLTAIC PANEL INTEGRATED WITH GROUND HEAT EXCHANGER FOR THERMAL MANAGEMENT
}

\author{
HUSSAIN H. AL-KAYIEM ${ }^{1, *} \&$ MAYAMEEN N. REDA ${ }^{2}$ \\ ${ }^{1}$ Solar thermal Advanced Research Center [STARC], Universiti Teknologi PETRONAS, \\ 32610 Seri Iskandar, Malaysia. \\ ${ }^{2}$ Institute of Thermodynamics, Technical University of Munich, Garching, Germany.
}

\begin{abstract}
In spite of high solar radiation being an advantage for the performance of solar photovoltaic (PV) panels, the caused high surface temperature of the panel surface reduces their efficiency, as well as lifetime span due to cyclic thermal stresses. PV panels are deteriorating due to two setbacks from a harsh climate: shallow temperatures during the night leading to condensation and overheating during the day leading to reduced efficiency. The present paper discusses and resolves the two setbacks in the PV performance by cooling the panel during the day and heating the panel during the night using water circulation in a ground embedded heat exchanger. Experimental and numerical methods were used to carry out the investigation on the influence of the proposed technique on the PV performance. Following the experiments, a computational model has been developed to simulate the experimental set-up. Two PV modules have been tested simultaneously in outdoor environment; one is bare and the second is integrated with ground heat exchanger. Results revealed that the integrated heat exchanger has managed to reduce the PV surface temperature by around $8^{\circ} \mathrm{C}$ during the daytime and rise the PV surface temperature by around $3^{\circ} \mathrm{C}$ more than the due temperature, at which condensation takes place during the night time. The developed technique has proved to be highly efficient as a PV thermal control method.
\end{abstract}

Keywords: Condensate in solar systems; Ground heat exchanger; integrated solar system; PV/T; Thermal control.

\section{INTRODUCTION}

Photovoltaic panels (PV) constitute the most commonly adopted solar-to-electricity conversion technique worldwide to alleviate the world electric energy demand. However, climate in the deserts is representing a challenging barrier for solar PV to be adopted. Heat and dust both have a negative impact on the performance, durability and electrical efficiency of the PV. The problem is associated with high temperature during the day and condensation formation after midnight. The cause of the problem and the resulting consequences are summarized in the chart shown in Figure 1.

Commercial solar cells convert solar irradiation into electric power at a relatively low efficiency, around $20 \%$. PV panel efficiency decreases due to high temperature by $0.4 \% / \mathrm{K}$, as noticed by Dorobantu et al. [1]. Because of this, researchers proposed many ideas to cool the $\mathrm{PV}$ panels during the day. PV integrated with a cooling method is called PV/T, referring to photovoltaic thermal combination.

Many PV cooling methods have been proposed and investigated. PV/T solar systems are beneficial devices, which enable production of electricity and heat simultaneously. Continuous water film flowing over the frontal surface of the PV module has been studied and analysed by many researchers. Dorobanţu et al. [1] presented their work on frontal water film cooling utilizing PV power plant installed at the University Politehnica of Bucharest. They used water film at $24^{\circ} \mathrm{C}$ flowing at $2 \mathrm{lit} / \mathrm{min}$, which reduced the temperature on the back of the PV from $48^{\circ} \mathrm{C}$ to $35.5^{\circ} \mathrm{C}$. The temperature difference between back-side and front-side of 

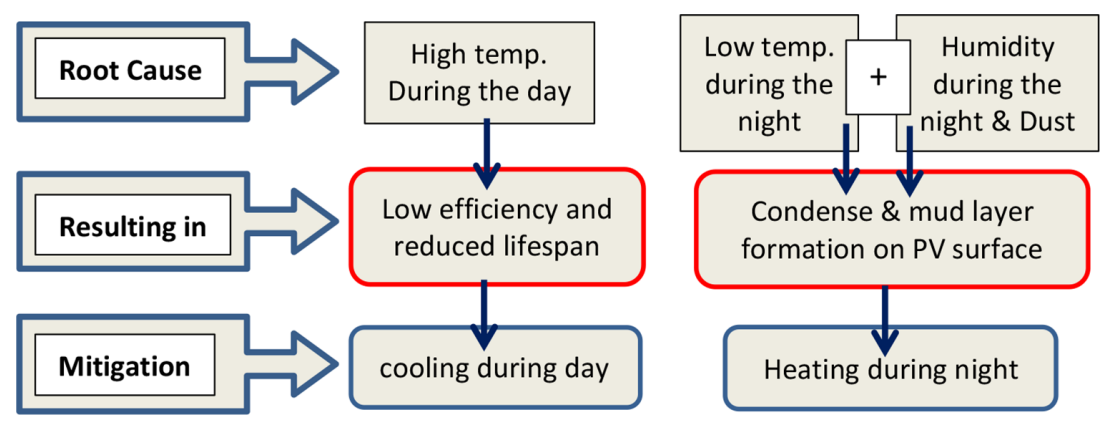

Figure 1: The root causes and the mitigation methods of the high temperature during daytime and condense/mud formation on the PV surface during the night.

the panel remains the same at about $7-8^{\circ} \mathrm{C}$. Experimental studies have been performed to compare the performance of a PV system combined with a cooling system consisting of a thin film of water running on the top surface of the panel. These studies contain the effects of the nominal power of array and system head on the operation of PV system by cooling the PV cells with a thin film of water (Krauter [2], Moharram et al. [3]).

Another proposed and widely investigated PV/T cooling method is by rear surface cooling. Bahaidarah et al. [4] evaluated the performance of a PV/T module by backside cooling and reported yielding a temperature reduction of $20 \%$, which resulted in an efficiency increase of the PV panel by $9 \%$. Hongbing et al. [5] investigated active cooling by attaching heat pipes beneath the PV panel, building up a PV-heat pipe (HP) combined system. They concluded that thermal efficiency decreased in the daytime; a turning point occurred in the afternoon and there was a minimum electrical efficiency in the daytime. Jakhar et al. [6] studied the rear side cooling by heat exchange with earth water and Chiasson et al. [7] by heat exchange with shallow water pond.

Another cooling method is by water spray on the frontal surface of the PV. A study by Odeh et al. [8] achieved cooling of the PV panel by water dripping on the upper surface of the PV panel and obtained an increase of about $15 \%$ in the system output at peak radiation conditions. A different investigation of front PV surface cooling was performed by Hosseini et al. [9], using a spray water cooling technique. Results showed that the cell power increased due to the spraying of water.

While the cooling of the PV module is needed only during day time, heating is needed in the night time to avoid condensation of air humidity on PV panels. This prevents the formation of mud in the presence of dusty winds, which increases maintenance costs and shortens the lifespan of the PV panels [10]. While Hegazy [11] investigated the effect of dust accumulation on flat plate solar collector, Kordzadeh [12] investigated the effects of nominal power of array and system head on the water pumping by PV set with the surface covered by a film of water and Al-Kayiem [13] investigated the condensation formation effect on the performance of the solar collector of solar chimney power plants. Hegazy [11] found that mud layers on the panels' surface reduce the transmissivity of the glass layer and thus also PV efficiency and Al-Kayiem et al. [13] found that the condensation alter the solar chimney functioning as the early hours after sunrise are consumed for evaporation of the condensate instead of heating the absorber. However, condensation film is encouraging mud formation and frequent cleaning is leading to scratching the surface, which in the medium term also leads to a drastic decline in the efficiency of solar systems, like PV, flat palate solar collectors and solar chimneys. 
Using the earth as a heat source or thermal buffer in a heating or cooling system is an attractive application from a thermodynamic point of view. Underground water cooling systems are potentially more efficient than conventional cooling water-to-air systems. Ground horizontal cooling loops are preferred in many situations due to a consistent temperature since the ground temperature is not different within a specific depth where the surface heat flux does not play any role ([14], [15]).

The ground heat exchanger (GHEX) is a concept of heat exchange between soil and circulating thermal medium, usually fluid flowing in pipe. At a certain depth in the ground, the soil temperature is almost constant throughout the day, unless there is harsh weather change. In tropical areas, the soil temperature below a certain depth is almost constant over the year (Bansal et al. [15]). Chel et al. [17] suggested that the soil can be used as a thermal sink for the cooling of PV panels. Various studies adopted the GHEX concept as earth-water heat exchangers and earth-air heat exchangers for air conditioning purpose, where water and air are the cooling media, respectively $[14,16,18,19]$. The GHEX pipes are buried in the ground at a particular depth, and the inlet of the tubes carries the hot water, which transfers the thermal energy from the high-temperature fluid to the soil, thus resulting in a decrease in outlet temperature [10-18].

In conclusion, most of the investigations and methods used in the PV/T approach are dealing with cooling of the PV during the day. No work is reported on mitigating the condensation during the night. The present article presents a CFD numerical procedure and the experimental validation approach achieved by site measurements. The article presents the results of the new novel method to mitigate both, high temperature during the day and condense formation during the night by integration of the PV/T panel with GHEX. The numerical method is developed by modeling of the experimental PV/T- GHEX in ANSYS FLUENT. Presented results are focusing on the validation of the CFD method, analysis of the GHEX and PV/T thermal conditions at various weather conditions.

\section{EXPERIMENTAL IMPLEMENTATION}

A developed experimental setup was designed and implemented under humid and warm climate conditions at the Universiti Teknologi PETRONAS (UTP) - Malaysia. The location of the site is at a latitude of $4.39^{\circ} \mathrm{N}$ and longitude of $100.9^{\circ} \mathrm{E}$.

\subsection{Description of experimental setup}

The experimental setup is shown schematically and physically in Figure 2. It comprises five primary components: solar PV panel, modified panel to a PV/T by installation of water pocket in the back, water circulation system with a pump, ground heat exchanger and set of measuring instrumentation system. Water as cooling/heating medium is circulating between the backside water pocket and the GHEX by pump running at controlled discharge for preselected flow rate. The PV and PV/T are subjected to the same weather conditions and are subjected to measurements and observations, simultaneously.

The GHEX is made of copper tube coil embedded in the ground. The tube has inner diameter of $0.015 \mathrm{~m}$, thickness of $0.003 \mathrm{~m}$ and a total length of $22.0 \mathrm{~m}$. The heat exchanger is installed at $0.8 \mathrm{~m}$ below the ground surface. This depth has been decided based on temperature distribution measurement of the ground in the experiment site. The measurements have been repeated for five days and the mean temperature values are considered for results analysis. At 0.8-m-depth and below, the temperature is almost constant. 


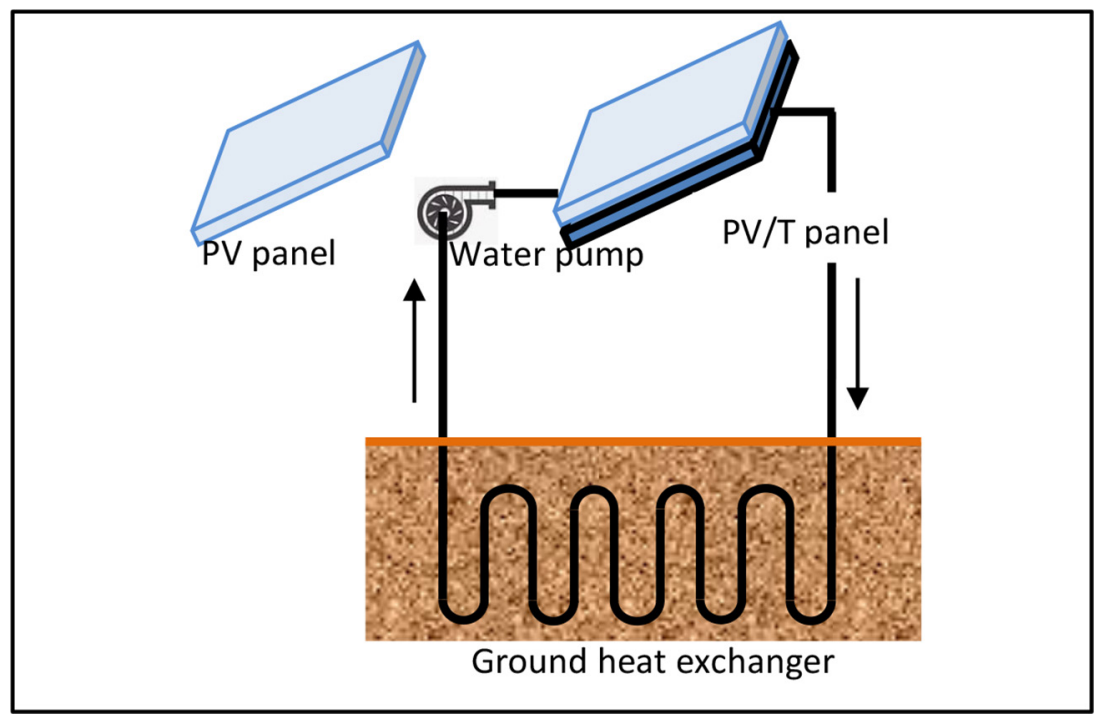

Figure 2: Schematic of the experimental set up including PV panel, PV/T panels and GHEX.

\subsection{Operational principles}

During the day, warm water flowing through the PV backside has been circulated through the GHEX, thus transferring heat to the soil and cooling the water. This process increases the soil temperature and store heat to the ground. However, during the night, when water flows through the ground, the storage heat increases the water temperature and heat the PV panel when circulating through the backside panel. The heat storage capacity of the ground is dependent on the thermal properties of the soil. Thermal conductivity of dry soil is measured and found to be about $0.2 \mathrm{~W} / \mathrm{m}^{2} \mathrm{~K}$.

\section{COMPUTATIONAL PROCEDURE}

The numerical analysis of the present work included a horizontal GHEX embedded underground. The simulation considered a block of the ground containing the GHEX, as shown in Figure 3. The selected ground block has 2-m-width $\times 3$-m-length $\times 2$-m-height. Those ground domain dimensions are large enough compared to the GHEX geometries for assuming adiabatic boundaries. The heat exchanger has similar geometries as in the experimental setup. The simulation has been conducted at three different depths, Z, of the GHEX installation: $0.5,0.8$ and $1.5 \mathrm{~m}$. The computational model was created to simulate the experimental case and impose extended boundary conditions to gain more insight on the effectiveness of the proposed idea of integrating the PV/T with underground embedded coil, GHEX.

The simulation was achieved by solving the conservation equations of mass, momentum and energy under the assumption of steady, compressible and viscid pipe flow. The equations of conservation of mass, momentum and energy are:

Continuity

$$
\nabla \cdot(\rho \vec{V})=0
$$


Momentum

$$
\rho(\vec{V} \cdot \nabla) \vec{V}=-\nabla \rho+\rho g+\nabla \cdot \tau_{i j}
$$

Energy

$$
\rho(\vec{V} \cdot \nabla \mathbf{u})=-(\nabla \cdot q)-p(\nabla \cdot \vec{V})-(\tau: \nabla \vec{V})+\dot{S}
$$

where $\vec{V}$ is the velocity vector, $u$ is the specific internal energy, $q$ is the heat flux $(=-k \nabla T)$, $p$ is pressure, $\tau$ is the shear tensor, $\dot{S}$ is a heat source (from/to ground) and $\tau: \nabla V$ is the change in internal energy due to viscous dissipation.

\subsection{Numerical modelling and meshing criteria}

The copper pipe loop and soil domain mesh is generated using the ANSYS meshing tool. In both domains, a hex-dominant method for reducing the number of cells is used. The cells in the copper pipe loops domain were kept uniform with a cell size of $0.2 \mathrm{~cm}$, which gave enough accuracy of the pipe temperature distribution. The internal water flow domain uses cell inflation on the interior of the pipe wall to resolve the near wall boundary layers within the fluid. Cell inflation meshing is recommended for modelling wall-bounded flow effects due to the turbulent boundary layer low gradient near the internal wall. It ensures that the grid cell close to the wall has a height smaller than the laminar sublayer, not in the algorithm region of the turbulent boundary layer (Lim et al. [20]). The discretization of these domains provides additional information about heat transfer and fluid flow characteristics within the system. In order to save computation time and since the flow characteristics are relatively simple, a high resolution of these features was not considered. The mesh was concentrated inside the soil pile. The size of the individual mesh elements varied greatly because of the large variation in domain sizes. The size variation of the domains provides challenges in keeping the cell count of the mesh low. The model residual convergence criteria were set to $1 \times 10^{-3}$. The CFD model mesh with the soil domain, the top and bottom of the soil pile and the copper pipe loops is displayed in Figure 3.

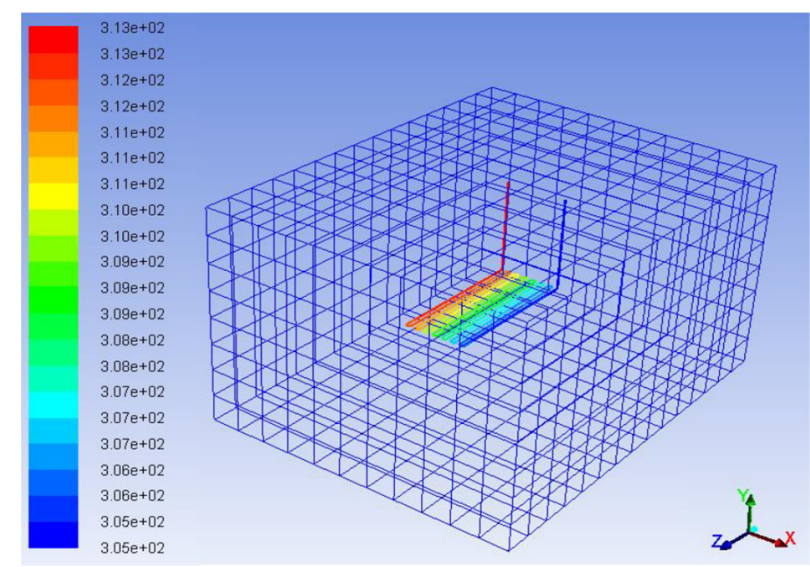

Figure 3: The soil domain and the copper pipe loops domain geometry. 


\subsection{Simulation procedure}

The simulation is performed numerically using control volume-based solver in the commercial software, ANSYS FLUENT. Reynolds-Averaged Navier-Stokes equations have been solved with a semi-implicit method for pressure-linked equations utilizing SIMPLE algorithm. The realizable $k-\varepsilon$ turbulence model with enhanced wall treatment and thermal effect option has been adopted. The $k-\varepsilon$ model is appropriate for wall-bounded and internal flows with small pressure difference across the flow passage (Lim et al. [20]). The $k$ - $\varepsilon$ model satisfies certain mathematical constraints on the Reynolds stresses and is consistent with the physics of turbulent flows. Robustness, computational economy and reasonable accuracy for a wide range of turbulent flows justify the $k-\varepsilon$ model popularity in engineering applications and heat transfer with fluid flow simulations (Ruzicka [21]).

The main parameters of the computational procedure are listed in Table 1. The numerical simulation has been carried out under the assumption of steady, incompressible and viscus flow conditions. The ambient temperature, solar irradiance and inlet water temperature are taken from the experimental data and input to the simulation. The computational domain is discretised adopting 3D-structured meshing criteria. The heat exchanger was simulated for different operating conditions following the experimental measurements conditions at various times of the day.

\subsection{Boundary Conditions}

For the simulation, the weather data acquired at the solar research site in UTP - Malaysia have been used. These considered the interactions of the soil with solar irradiation at the ground surface. Also, wind speed and ambient air temperature during the measurement time have been utilized as input parameters to the simulation. The applied boundary conditions used in the simulations are given in Table 2.

Table 1: CFD simulation parameters.

\begin{tabular}{ll}
\hline Parameter & Description \\
\hline Mesh Elements & 3D Structured mesh, hex-dominant \\
Numbers of elements/nodes & 228390/289388 \\
Solver & 3D steady-state \\
Pressure velocity coupling & Phase Coupled SIMPLE \\
Turbulence model & Realizable $k-\varepsilon$ \\
\hline
\end{tabular}

Table 2: Boundary conditions adopted in the simulation.

\begin{tabular}{ll}
\hline Parameter & Value \\
\hline Water mass flow rate $(\mathrm{kg} / \mathrm{s})$ & 0.02778 \\
Water inlet temperature $(\mathrm{K})$ & According to the measurement data \\
Soil thermal diffusivity $\left(\mathrm{m}^{2} / \mathrm{s}\right)$ & $1 \times 10^{-6}$ \\
Depth $(\mathrm{m})$ & $0.5,0.8,1.0$ and 1.5 \\
Solar irradiance $\left(\mathrm{W} / \mathrm{m}^{2}\right)$ & According to the measurement data \\
\hline
\end{tabular}


Table 3: Material properties involved in the simulations.

\begin{tabular}{lllll}
\hline & & \multicolumn{3}{c}{ Ground (soil) } \\
Property & Pipe (copper) & Dry & Wet & Water \\
\hline Density $\left(\mathrm{kg} / \mathrm{m}^{3}\right)$ & 8,940 & 1,555 & 1,905 & 1,000 \\
Conductivity $(\mathrm{W} / \mathrm{m} \cdot \mathrm{K})$ & 250 & 0.21 & 2.08 & 0.6 \\
$\mathrm{Cp}(\mathrm{kJ} / \mathrm{kg} \cdot \mathrm{K})$ & 390 & 875 & 1,480 & 4,184 \\
Viscosity $(\mathrm{kg} / \mathrm{m} \cdot \mathrm{s})$ & - & & - & $1.1003 \times 10^{-3}$ \\
\hline
\end{tabular}

The values of the main thermodynamic properties of the materials included in the simulation are shown in Table 3.

\section{RESULTS AND DISCUSSIONS}

The numerical simulation has been carried out at controlled water flow rate of 1.6 LPM. The experimental conditions during the measurement are essential to be identified prior to commencing the discussion of the results.

\subsection{Experimental results}

The experimental measurements were carried out first on the ground thermal conditions and then on the PV and PV/T-GHEX system. The measurements have been repeated for many days and an average over 5 days is selected for presentation.

\subsubsection{Ground temperature results}

The ground temperature at various depths is essential for making a correct decision on the depth at which the tube coil should be buried. Figure 4 shows the transient measured ground temperature at 0.5 and $0.8 \mathrm{~m}$ depth. The temperature results are almost identical in the early morning hours. Divergence begins after 11.30 AM in the morning until it reaches its maximum value at around 4.30 PM. Two conclusions could be drawn from those measurements. First, it is clear that the soil temperature is almost constant at $0.8 \mathrm{~m}$ depth with slight increase in the afternoon, as the solar radiation with high irradiance and high incidence. Second, the

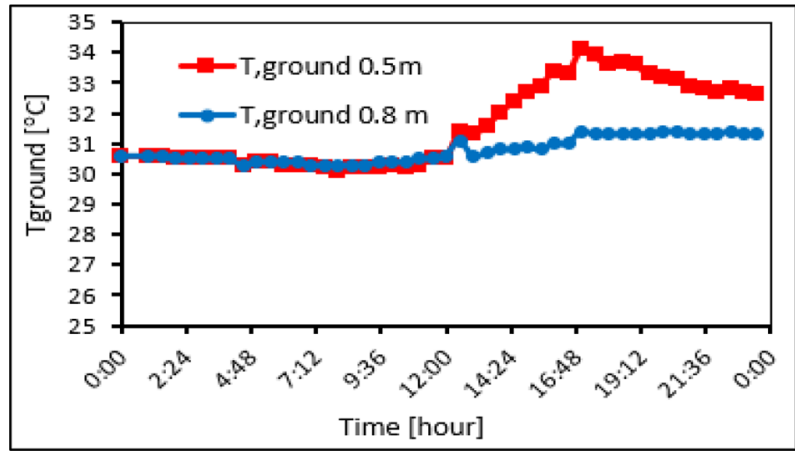

Figure 4: Measured ground temperature at $0.5 \mathrm{~m}$ and $0.8 \mathrm{~m}$ depth. Dry soil, average over 5 days measurements at UTP - Malaysia. 




Figure 5: Transient behaviour of the measured temperatures of the PV, PV/T and the solar irradiation over a day. (Mean of 5 days repeatability in October for a water flow).

temperature of ground at $0.5 \mathrm{~m}$ depth is not suitable for the installation of the GHEX as it is relatively high and the heat removal from the hot water will be inefficient.

\subsubsection{PV Modules temperatures results}

Figure 5 shows the measured temperatures on the surfaces of the PV, PV/T panels and the solar irradiation in October month.

The thermal control system managed to reduce the PV/T panel temperature by about $8 \mathrm{~K}$ over the hot and high solar irradiance period during the day. This temperature reduction is enough to keep the PV panel temperature near the normal operating condition of about $40-45^{\circ} \mathrm{C}$. During the condensation time (3:30 AM to 7:30 AM), the thermal control system managed to keep the PV surface temperature above the dew temperature by about $2-4^{\circ} \mathrm{C}$. By this thermal control system, the PV efficiency can be increased by $10 \%$ and nocturnal condensation can be avoided.

\subsection{Simulation results}

The numerical procedure developed in this research is aimed to simulate the operational performance of GHEX that is hypothesised to enhance the performance of a PV/T system.

\subsubsection{Validation of computational procedure}

Prior to presenting and discussing the numerical results, the computational procedure is validated. The validation has been achieved through comparison between the numerical 


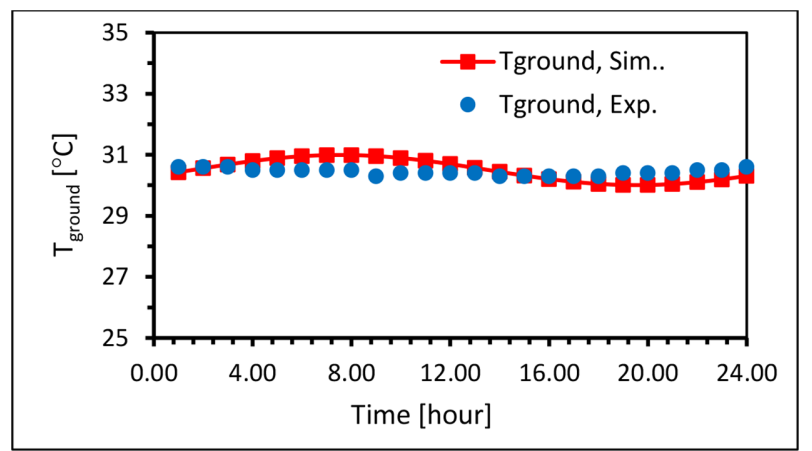

Figure 6: Validation of the numerical procedure by comparison between measured and predicted temperatures of the ground. (Dry soil at 0.8-m-depth).

prediction and experimental measurements. As a numerical analysis targeting ground thermal simulation and GHEX simulation, the validation procedure is based on both. Figure 6 represents validation by comparing the experimental measurements and simulation prediction of dry soil ground temperatures at $0.8 \mathrm{~m}$. The goodness of the simulation is fairly clear in terms of the trend and the deviation.

However, the simulation is over-predicting the ground temperature during the daytime and under-predicting the ground temperature after the midnight. The maximum relative error is around $1.9 \%$, which indicates that the simulation is valid to predict the ground temperature.

Comparison between various cases of measured and simulated ground temperatures is presented in Table 4. The results in the table demonstrate that the soil conditions, wet or dry, highly influence the temperature profile in the ground. Both, experimental and numerical results show that the dry soil temperature is higher than the wet soil temperature, under the same weather conditions.

Experimental water temperature at outlet of the GHEX as measured experimentally and that predicted numerically by the simulation are compared by referring to Figure 7 . The short-term behaviour of the fluid outlet temperature was compared as obtained experimentally and numerically during every $1 \mathrm{~h}$ at a depth of $0.8 \mathrm{~m}$. The maximum and mean differences between the simulation and experimental results are about $3.2 \%$ and $2.2 \%$, respectively. So, it is reasonable to say that the outlet fluid temperature shows reasonable agreement with the experimental data. The numerical model and experimental data matched well in this timeframe, whereas a maximum deviation of $0.6 \mathrm{~K}$ was observed at $5 \mathrm{PM}$.

\subsubsection{Simulation results of ground temperature}

Figure 8 shows the temperature profiles in the soil pile at two different buried GHEX depths, $0.5 \mathrm{~m}$ and $1.0 \mathrm{~m}$, at $12 \mathrm{PM}$, October 11 . The temperature profiles show that under realistic

Table 4: Measured and simulated ground temperatures at 12:00 PM at 0.8-m-depth.

\begin{tabular}{|c|c|c|c|c|}
\hline \multirow{2}{*}{$\begin{array}{l}\text { Ground } \\
\text { type }\end{array}$} & \multirow{2}{*}{$\begin{array}{l}\text { Solar irradiance } \\
\left(\mathrm{W} / \mathbf{m}^{2}\right)\end{array}$} & \multicolumn{2}{|c|}{ Ground temperature $\left({ }^{\circ} \mathrm{C}\right)$} & \multirow[b]{2}{*}{$\%$ of difference } \\
\hline & & Measured & Simulated & \\
\hline Dry soil & 935 & 30.27 & 30.7 & $1.4 \%$ \\
\hline Wet soil & 1051 & 29.1 & 28.6 & $1.75 \%$ \\
\hline
\end{tabular}




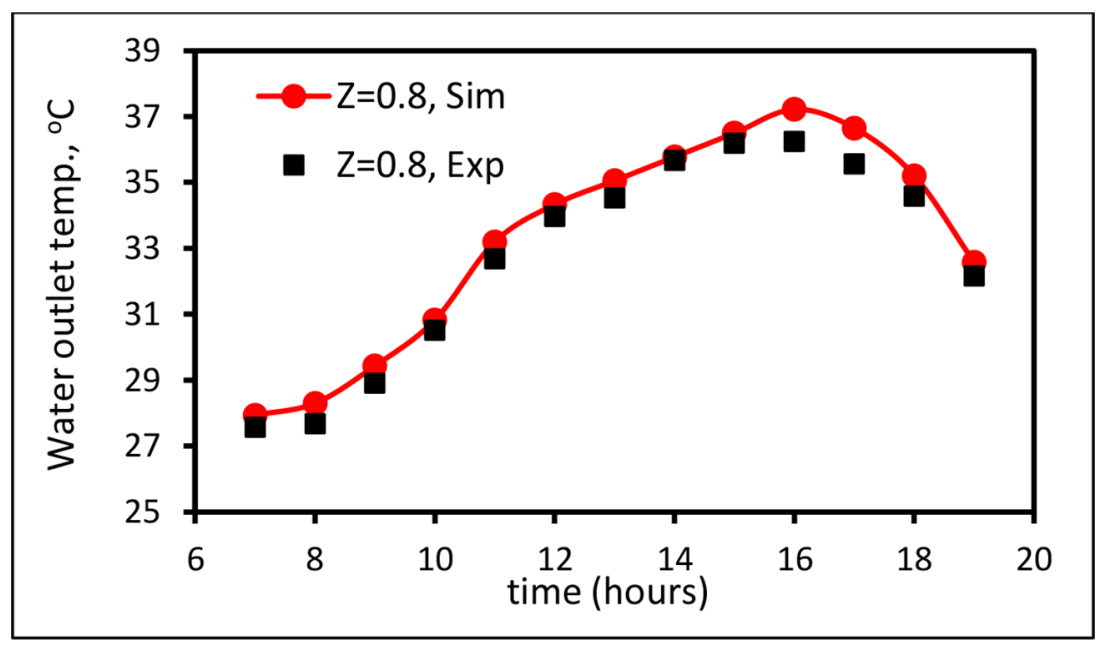

Figure 7: Comparison between the numerical prediction and experimental measurement results of outlet water temperature from the GHEX installed at $0.8 \mathrm{~m}$ depth.

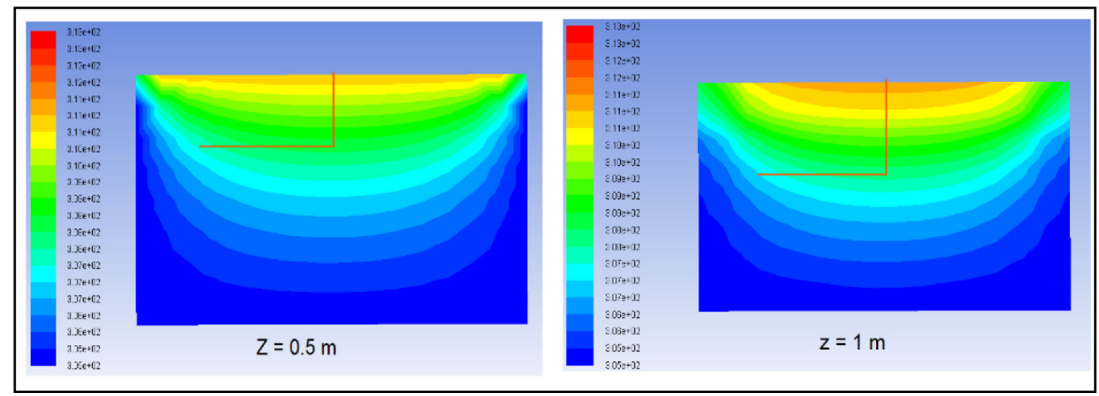

Figure 8: Temperature profile in dry soil of the simulation block, considering the presence of the GHEX at 0.5 and $1.0 \mathrm{~m}$ depth.

weather conditions, the soil temperature varies minimally at 1.0 -m-depth, whereas temperature is almost constant below a depth of around $1.5 \mathrm{~m}$. This is the ideal location for the ground heat exchanger as it was not affected much by the ambient weather conditions. At 1.5-m-depth and below, it is possible to obtain the maximum temperature between circulatory water inside the GHEX and the surroundings.

\subsubsection{Simulation results the ground heat exchanger}

Figure 9 displays the heat dissipation in the buried GHEX at 0.8-m-depth, at 12:00 PM. Hot water flows in the GHEX at around $313 \mathrm{~K}$ and leaves at around $308 \mathrm{~K}$. The GHEX managed to reduce the water temperature by around $5 \mathrm{~K}$. This demonstrates the correctness of the hypothesis and the proposed technique for reducing the PV surface temperature.

\subsubsection{Ground heat exchanger performance}

Figure 10 shows the water outlet temperature from the GHEX at various times when the GHEX is located at depths of $0.8 \mathrm{~m}, 0.5 \mathrm{~m}$ and $1.5 \mathrm{~m}$ in dry soil. With larger depths of the copper pipe loop, the overall heat transfer area towards the colder soil is also growing. 


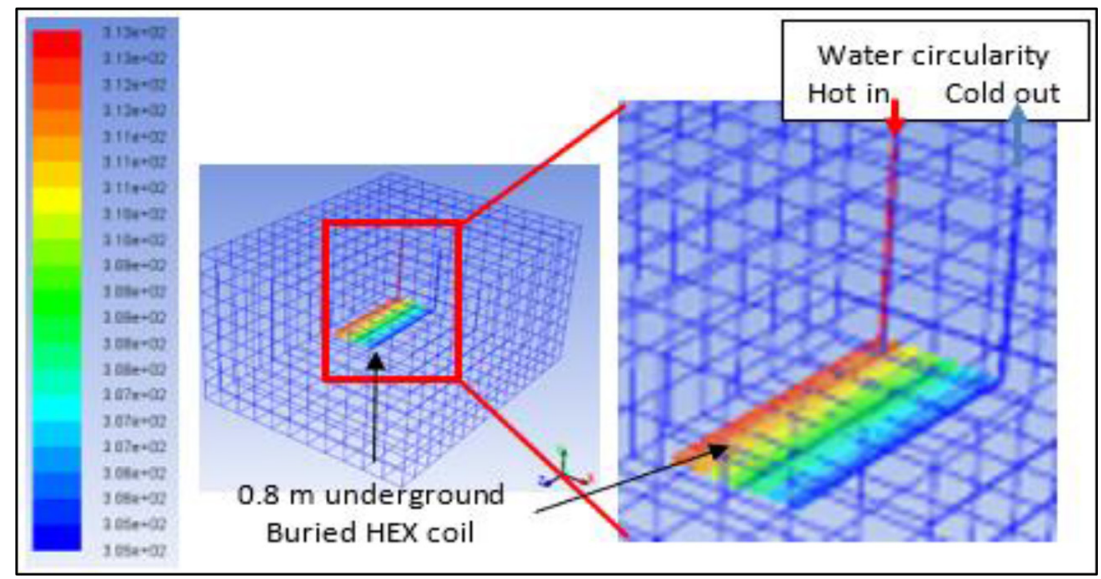

Figure 9: Temperature profile of the GHEX, at 0.8-m-depth, October 11th, 12:00 PM. (solar irradiance $=935 \mathrm{~W} / \mathrm{m}^{2}$ ).



Figure 10: The predicted temperature of water at outlet from the GHEX, from 7:00 AM to 7:00 PM.

Besides, the water temperature was less affected by the thermal condition of the soil surface for a larger burial depth of the pipe. Therefore, the water outlet temperature decreases with increasing depth.

\subsection{Effect of weather conditions on the PV-GHEX system performance}

The PV-GHEX system has been run for different cases; in every case, one of the weather data is changed and other data are fixed.

\subsubsection{Effect of wind speed}

Figure 11 shows the effect of wind velocity on the PV/T-GHEX panel surface temperature. The results show that when the wind velocity changed from 2 to $12 \mathrm{~m} / \mathrm{s}, \mathrm{PV}$ glass temperature changed from $304.6 \mathrm{~K}$ to $301.7 \mathrm{~K}$ during the night and from $292.6 \mathrm{~K}$ to $292.2 \mathrm{~K}$ during the day. For every $4 \mathrm{~m} / \mathrm{s}$ rise in wind velocity, the PV glass temperature is reduced by $1.2 \mathrm{~K}$ 




Figure 11: Simulated PV/T surface temperature for different wind velocity.

during daytime. For every $4 \mathrm{~m} / \mathrm{s}$ rise in wind velocity, the glass temperature is reduced by 0.3 $\mathrm{K}$ during the night-time. This is because the air flow will increase the convective heat transfer loses, which will decrease the glass surface temperature.

\subsubsection{Effect of ambient temperature}

Figure 12 presents the effect of ambient air temperature, $T_{\text {air }}$ on the system surface temperature. For air temperature changing from $8{ }^{\circ} \mathrm{C}$ to $48{ }^{\circ} \mathrm{C}$, the night glass surface temperature, $T_{\text {glass }}$, changes from $288.7 \mathrm{~K}$ to $304.8 \mathrm{~K}$ and the day glass temperature changes from $301.4 \mathrm{~K}$ to $317.6 \mathrm{~K}$. For every $10 \mathrm{~K}$ rise in $T_{\text {air }}, T_{\text {glass }}$ increases by $4 \mathrm{~K}$. This increment in the PV glass surface temperature is due to the glass exchanging heat with the surroundings through convection as well as radiating heat from and to the atmosphere through radiation.

\subsubsection{Effect of dew point temperature}

Figure 13 shows the PV-GHEX system surface temperature for one day. The dew point temperature is changed from $1{ }^{\circ} \mathrm{C}$ to $15^{\circ} \mathrm{C}$ and other weather data were fixed. The PV/T glass temperature changes from $296.3 \mathrm{~K}$ to $295 \mathrm{~K}$ during the condensation time over the $1^{\circ} \mathrm{C}$ to $15^{\circ}$ $\mathrm{C}$ increase in the dew point temperature. While the glass temperature is reduced by $2.5 \mathrm{~K}$

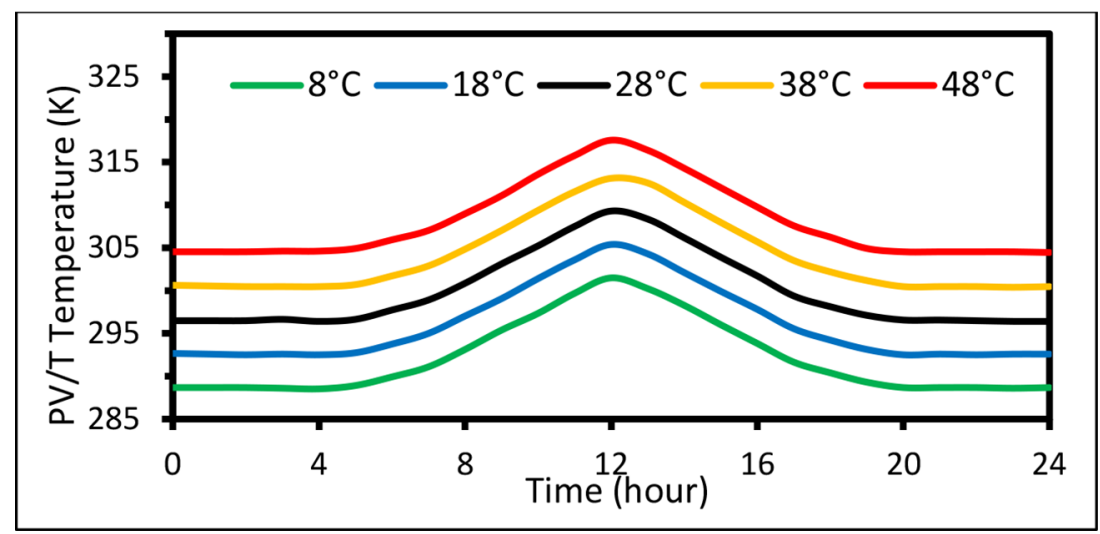

Figure 12: PV/T surface temperature for different ambient temperature. 


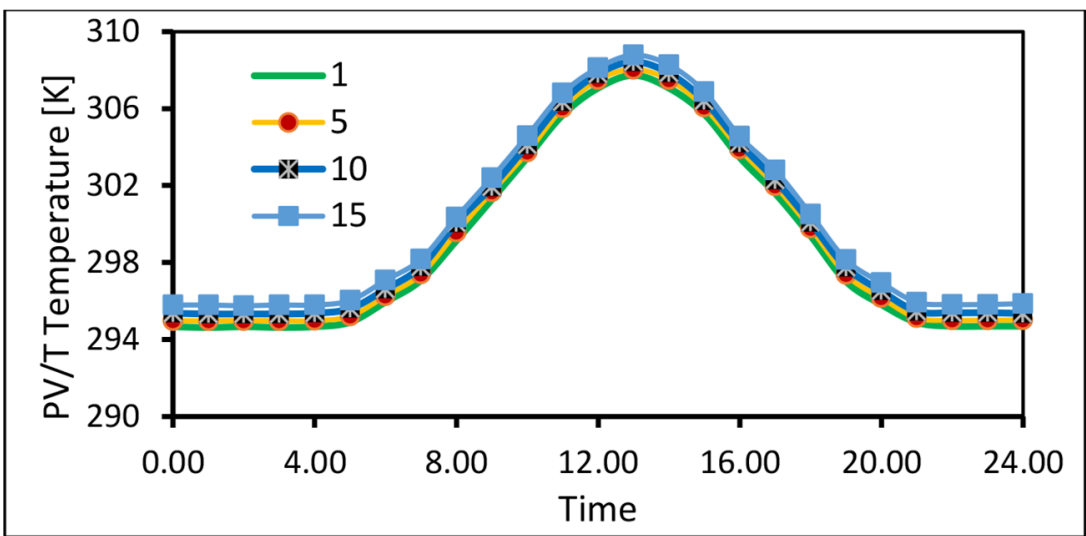

Figure 13: Glass surface temperature for different dew point temperature and other weather data are fixed.

during the daytime. For every $5 \mathrm{~K}$ rise in dew temperature, the glass temperature increases by $0.4 \mathrm{~K}$ and $2.5 \mathrm{~K}$ during the night time and daytime, respectively.

\section{CONCLUSIONS}

It is demonstrated that installation of water pocket at the back of the PV and connected to ground heat exchanger would enhance the PV/T performance. Experimental and numerical assessment proved the functionality of the proposed method to mitigate the PV problems of high temperature in the day and condensation formation in the night. Results show that the GHEX cools the water in the daytime by around $8 \mathrm{~K}$, leading to improved PV daily efficiency by about $9.0 \%$. Experimental measurements revealed that the GHEX has contributed to warming up the PV/T in the night, resulting in elimination of the moisture condensation on the PV surface. On other hand, ground temperature profile measurement and simulation show that the wet soil has lower temperature than the dry soil.

\section{ACKNOWLEDGMENTS}

The authors acknowledge PETRONAS - Malaysia for the financial support of the research under research grant YUTP-FRG, CS: 015LC0-206. Also, Universiti Teknologi PETRONAS (UTP), Malaysia is acknowledged for the logistic and technical support to carry out the research in the solar site of the solar thermal advanced research centre [STARC].

\section{REFERENCES}

[1] Dorobanţu, L., Popescu, M., Popescu, C. \& Crăciunescu, A., Experimental assessment of PV panels front water cooling strategy. International Conference on Renewable Energies and Power Quality (ICREPQ'13), Bilbao, Spain, pp. 1009-1012, 2013.

[2] Krauter, S., Increased electrical yield via water flow over the front of photovoltaic panels. Solar Energy Materials and Solar Cells, 82, pp. 131-137, 2004. https://doi.org/ 10.1016/j.solmat.2004.01.011

[3] Moharram, K.A., Abd-Elhady, M., Kandil, H. \& El-Sherif, H., Enhancing the performance of photovoltaic panels by water cooling. Ain Shams Engineering Journal, 4, pp. 869-877, 2013. https://doi.org/10.1016/j.asej.2013.03.005 
[4] Bahaidarah, H., Subhan, A., Gandhidasan, P. \& Rehman, S., Performance evaluation of a PV (photovoltaic) module by back surface water cooling for hot climatic conditions. Energy, 59, pp. 445-453, 2013. https://doi.org/10.1016/j.energy.2013.07.050

[5] Hongbing, C., Xilin, C., Sizhuo, L. \& Sai, C., Experimental study on the energy performance of PV-HP water heating system. Energy Procedia, 75, pp. 294-300, 2015. https://doi.org/10.1016/j.egypro.2015.07.351

[6] Jakhar, S., Soni, M. \& Gakkhar, N., Performance analysis of photovoltaic panels with earth water heat exchanger cooling. MATEC Web of Conferences, 2016.

[7] Chiasson, A.D., Spitler, J.D., Rees, S.J. \& Smith, M.D., A model for simulating the performance of a shallow pond as a supplemental heat rejecter with closed-loop groundsource heat pump systems. Ashrae Transactions, 106, p. 107, 2000.

[8] Odeh, S. \& Behnia, M., Improving photovoltaic module efficiency using water cooling. Heat Transfer Engineering, 30, pp. 499-505, 2009. https://doi.org/10.1080/0145763 0802529214

[9] Hosseini, R., Hosseini, N. \& Khorasanizadeh, H., An experimental study of combining a photovoltaic system with a heating system. World Renewable Energy Congress, Sweden; 8-13 May; 2011; Linköping; Sweden, pp. 2993-3000, 2011.

[10] Reda, M.N, Spinnler, M., Al-Kayiem H.H. \& Sattelmayer, T., Analysis of ground thermal control systems for solar photovoltaic performance enhancement. WIT Transactions on Ecology and the Environment, 246, pp. 41-50, 2020.

[11] Hegazy, A.A., Effect of dust accumulation on solar transmittance through glass covers of plate-type collectors. Renewable Energy, 22(4), pp. 525-540, 2001. https://doi. org/10.1016/s0960-1481(00)00093-8

[12] Kordzadeh, A., The effects of nominal power of array and system head on the operation of photovoltaic water pumping set with array surface covered by a film of water. Renewable Energy, 35, pp. 1098-1102, 2010. https://doi.org/10.1016/j.renene.2009.10.024

[13] Al-Kayiem, H.H., Mohammed A. Aurybi, M.A. \& Gilani, S.I.U., Influence of canopy condensate film on the performance of solar chimney power plant. Renewable Energy 136, pp. 1012-1021, 2019. https://doi.org/10.1016/j.renene.2019.01.067

[14] Yusof, T.M., Anuar, S. \& Ibrahim, H., A review of ground heat exchangers for cooling application in the Malaysian climate. Journal of Mechanical Engineering and Sciences, 8, pp. 1426-1439, 2015. https://doi.org/10.15282/jmes.8.2015.17.0139

[15] ASHRAE Handbook, American Society of Heating, Refrigeration and Air-Conditioning Engineers, Inc, 2005.

[16] Bansal, V., Misra, R., Agrawal, G.D. \& Mathur, J., Performance analysis of earth-pipeair heat exchanger for winter heating. Energy and Buildings, 41, pp. 1151-1154, 2009. https://doi.org/10.1016/j.enbuild.2009.05.010

[17] Chel, A., Janssens, A. \& De Paepe, M., Thermal performance of a nearly zero energy passive house integrated with the air-air heat exchanger and the earth-water heat exchanger. Energy and Buildings, 96, pp. 53-63, 2015. https://doi.org/10.1016/j. enbuild.2015.02.058

[18] T'Joen, C., Liu, L. \& De Paepe, M., Comparison of earth-air and earth-water ground tube heat exchangers for residential application. International Refrigeration and AirConditioning Conference, Purdue University, Herrick Laboratories, 2012. 
[19] Chel, A., Janssens, A. \& De Paepe, M., Thermal performance of a nearly zero energy passive house integrated with the air-air heat exchanger and the earth-water heat exchanger. Energy and Buildings, 96, pp. 53-63, 2015. https://doi.org/10.1016/j. enbuild.2015.02.058

[20] Lim, D. C., Al-Kayiem, H. H. \& Kurnia, J. C., Comparison of different turbulence models in pipe flow of various Reynolds numbers. AIP Conference Proceedings 2035, 020005, 2018.

[21] Ruzicka, P., Modeling of boundary layer and the influence on heat transfer with help of CFD. AIP Conference Proceedings, 2047, 020021, 2018. 